Fecha de recepción: mayo 2021 Fecha de aceptación: junio 2021 Versión final: julio 2021

\section{Consideraciones dialógicas de los contenidos físicos museísticos convertidos en formatos virtuales a través del diseño}

Erika Mayoral ${ }^{(1)}$

Resumen: Las exposiciones de los museos en la actualidad constituyen historias con un principio y un desarrollo para llegar a un final, esto facilita la comprensión de una narrativa que fue delimitada previamente para tener un sólido argumento curatorial. Tanto la lectura como el contenido temático de los museos son aspectos posibles de percibir en los discursos expositivos planteados en las salas de exhibición con recorridos que incluyen múltiples objetos junto con soportes audiovisuales tanto analógicos como digitales. A través de una gran labor museológica dichos recintos habilitan espacios para que sus visitantes experimenten, de diferentes formas, tanto los tópicos como las historias que desean narrar, y uno de sus grandes aliados ha sido el diseño. Esta herramienta sintetiza relatos, historias e información de manera eficaz, como por ejemplo, el uso del diseño en las líneas de tiempo. Tal relación dialógica entre el contenido museístico y el diseño ha sido expandida de tal manera que se han llegado a crear museos y exposiciones virtuales, de tal manera que a partir de un "clic" en una computadora o celular es posible dar un recorrido en exposiciones nacionales e internacionales. Esto ha otorgado retos inmensos de adaptación de los relatos museísticos físicos a páginas web con diseños y soportes digitales atractivos que han ido evolucionando junto con la propia tecnología.

Palabras clave: Dialógico - Museología - Diseño - Virtualidad - Integración - Interacción

[Resúmenes en inglés y portugués en la página 118 ]

(1) Artista, investigadora independiente y docente mexicana. Licenciada en Marketing por la UNITEC. Graduada con mención honorífica de la Maestría en Artes de la UNAM donde obtuvo también una residencia de investigación en la University at Buffalo. Ha dado tanto conferencias como talleres de arte y su obra ha sido presentada en importantes festivales, museos y galerías tanto en su país como internacionalmente. 


\section{Introducción}

Existe una simbiosis indestructible entre la organización de exposiciones dentro de los museos, y las variantes de la planeación y el diseño de las mismas. El acto de creación genera diferentes medios de expresión visual, de alguna manera, el diseño en el campo de la institución museística cubre sus objetivos centrados en la reflexión, educación, aprendizaje y el servicio público. Uno de los retos más grandes de estas instituciones, es captar y conservar la atención del público ya consolidado y del nuevo. A partir del diseño, dentro de las exposiciones se plantea crear un espacio de diálogo con narrativas y propuestas cautivadoras. Con este escrito, se persigue el objetivo de poner en relieve importancia de convertir los contenidos de exposiciones en formatos virtuales a partir de estrategias propias del diseño.

\section{Museo como espacio dialógico en comunión con el diseño}

Al realizar un acercamiento a las definiciones del concepto de museo, en primera instancia se encuentra la del diccionario de la Real Academia Española que lo describe como "el lugar en que se conservan y exponen colecciones de objetos, artísticos, científicos, etc." (RAE, 2020). Por su parte, la agencia federal norteamericana, el Institute of Museums and Library Services (IMLS) lo cataloga como "una institución pública o privada sin fines de lucro organizada de manera permanente para fines esencialmente educativos o estéticos, que a través de su personal profesional posee o utiliza objetos tangibles, los cuida y exhibe al público regularmente" (OMA, 2021). Como se observa, el IMLS otorga una definición un poco más amplia dándole no sólo prioridad a la conservación y a la exposición de las colecciones sino también concediéndole importancia al rol pedagógico y a la experiencia estética. Es posible indagar otras acepciones de múltiples asociaciones de museos pero es necesario enfocar la atención en la que ofrece la organización creada entre los años 1946 y 1947 que es la International Council of Museums (ICOM), la cual a partir de la evolución y necesidades de los museos, estableció la siguiente definición en 2007:

Un museo es una institución permanente sin ánimo de lucro al servicio de la sociedad y a su desarrollo, abierto al público, que adquiere, conserva, investiga, comunica y exhibe el patrimonio material e inmaterial de la humanidad y su entorno con fines de educación, estudio y disfrute. (ICOM, 2021, s/p)

A partir de esto, el museo dejó de ser un lugar cuasi sacro, inalcanzable y estático para abrirse a la posibilidad de transmitir mensajes a su público, atrayendo su atención, interesándose en crear y fortalecer una relación institución-individuo. En este sentido, el museo ha tenido que adaptarse a entornos sociales donde ahora el público se ha convertido en una de sus grandes prioridades, de tal forma que los museos comienzan a ser una especie de dinamizadores sociales económicos y culturales de su entorno (Mateos, 2011). Por supuesto no hay que olvidar sus funciones básicas de los museos, las cuales tienen su origen 
en el siglo XVIII y que incluyen, en términos generales, las de guardar la colección o el patrimonio cultural, conservarlo, investigarlo y exponerlo.

En cuanto al concepto de exposición, Maure explica que "es un método que constituye una de las más importantes plataformas de diálogo y concienciación de que dispone el museólogo con la comunidad...” (1996, p. 35). Más aún, para diseñar una exposición, se parte de textos con los que organizar, formar, conectar y posibilitar tanto el diálogo como los vínculos, aprendizajes e interacciones; siendo éstos, objetivos prioritarios que orientan la planeación, el diseño museográfico, la ruta de la exposición y ciertos procesos de comprensión, experiencia, contextualización e interpretación.

De esta manera, los textos de los museos deben entenderse y evaluarse en el contexto desde el que se enuncian, otorgando una comunicación clara, consistente, reflexiva y hasta posiblemente afectiva, contribuyendo a propósitos específicos de cada recinto así como a las demandas de sus visitantes. Por lo tanto, los textos de base y los que resulten dentro de la exposición, podrán cobrar sentido, Ochoa ofrece la siguiente reflexión:

La ética exige un pensamiento convertido en lenguaje, no sólo en razón de su dimensión necesariamente pública sino también porque así se pone en evidencia el carácter no meramente declarativo del lenguaje, es decir, todo diálogo para ser efectivamente tal exige una voluntad de compromiso. La interpretación supone comunicación y, por ende, diálogo [...] el sentido es un descubrimiento estrictamente referencial, tanto porque se trata de un descubrimiento que se supone compartido por el emisor e intérprete, como porque el sentido remite al texto más allá de sí mismo, lo pone en relación con un con-texto y con una totalidad de sentido. (2009, p. 85)

De tal manera que el lenguaje del diseño aplicado a exposiciones depende del ambiente en el que se inscribe esta exposición y con el que dialoga. Dentro de la propuesta cobra un rol relevante el diseño visual ya que necesita ser el gatillo que detone la conexión con el público emitiendo la información. Es por ello que uno de los roles fundamentales que puede desempeñar el diseñador de una exposición es el de respaldar visualmente su narrativa. Otro enfoque del diseño aplicado a las exposiciones consiste en usar los espacios de manera idónea para establecer una comunicación que destaque materiales, vitrinas, tecnología y utilice eficientemente el equilibrio del diseño para generar unidades armónicas que establezcan el ir y venir dialógico institución-receptor.

Es por ello que al establecer lo que los curadores llaman un Statement Curatorial o Texto Curatorial es crucial ya que se parte de una idea general para llegar a algo más particular, otorgando una guía, cumpliendo así los objetivos específicos de cada exposición. En esta guía se plantea aquello que realmente se desea comunicar, su importancia, a quién va dirigido, abarcando también esferas de investigación, redacción, diseño y por supuesto está explicitado el sector de la comunidad a la que está orientada la exposición en un próximo futuro. Estas estrategias de diseño, van aunadas a una práctica curatorial desde la perspectiva de gestión así como a una estrategia que construye profundos vínculos entre museos y personas. Una de las herramientas centrales son, por ejemplo, las cédulas que se diseñan como un elemento ideal que forma parte de la exposición, debiendo ser amigables, capaces de 
responder preguntas, sabiendo lo que hay detrás e indicando componentes que quizás puedan pasar desapercibidos en un principio por la audiencia, considerándolas tal vez como un recurso de conversación entre quienes planearon la exposición y su público final. Es necesario entonces poner en la mira la experiencia total de quien visita un museo con la finalidad de establecer mecanismos óptimos ya que las cédulas son las mediadoras entre el público y el objeto presentado (ya sea este físico o en otros múltiples soportes) pues otorgan visibilidad a las ideas centrales de la exposición dándoles voz. Silvia Ramírez (2016, p. 132) considera que las cédulas deberían tener las siguientes características en cuanto a la redacción y comunicación de ideas:

- Tener una idea principal y regresar a ella cada vez que sea necesario. Partir de lo general a lo particular, lo que lleva al visitante a descubrir nuevos caminos que le permiten recordar detalles de la exposición sin perder la idea principal.

- Si se pretende incluir preguntas en las cédulas, siempre deben ir acompañadas por una sugerencia que despierte la curiosidad y la motivación del visitante por experimentar, conocer y aprender lo que se le propone.

- El contenido expresado, debe ser completamente entendible, es decir, tener en cuenta el público meta, sin embargo, ha de usar un vocabulario común para todo tipo de público.

- Emplear frases atractivas fáciles de recordar, que a la atención del visitante le parezcan interesantes para comentar en el momento de su visita o posterior a ella.

- Cada cédula propuesta debe tener un propósito particular por separado y, en conjunto, constituir un mensaje común: el de la exposición

- La información tiene que ir acompañada por las palabras exactas y comprensibles, pensadas y formuladas en el mismo camino del proceso de producción de la exposición.

- La cédula debe comprender al visitante para que este a su vez, la comprenda. Es decir, el material necesita crearse en cuestionamiento y reflexión del público al cual será dirigido.

- Clarificar conceptos, simplificar mensajes y eliminar términos confusos.

En cuanto al diseño per se de las cédulas Ramírez (2016, p. 133) enuncia lo siguiente:

- Si se utilizan palabras e imágenes, siempre han de usarse aquellas como apoyo de estas y no la imagen como apoyo del texto pues de lo contrario, estará indicando por sí misma que el texto no se entiende.

- El tamaño de la letra debe ser de más de un centímetro. Es la medida adecuada para una buena lectura, no sólo para "escanear" el texto.

- El tipo de letra que se utilice tiene que ser común para la gente, como Arial, Helvética o Gill Sans. 
- Relacionar las cédulas ya sea con imágenes tangibles o imágenes abstractas que colaboren a un mejor recordatorio de la información por parte de la gente.

- Pensar en las cédulas como parte esencial de la exposición, a pesar de que se trabajan de manera particular, siempre forman parte de un equipo donde, junto con más elementos, dan uno o más mensajes.

- La longitud de las líneas no debe rebasar los 45 caracteres, esto es, entre 8 y 10 palabras.

- Utilizar fondo claro con letras oscuras, en vez de un fondo oscuro con letras claras facilitará la lectura y evitará el cansancio en el proceso. El fuerte contraste favorece la lectura pues no se mimetiza la letra con el fondo, causando confusiones.

- Acortar el número de palabras aunque el discurso sea extenso, hay que encontrar la manera de decir mucho con pocas, utilizar solo las necesarias evitando al final que no se diga nada en concreto.

Es importante resaltar que las cédulas pueden ser un medio idóneo para la apertura al diálogo con el público que visita los museos, ayudando a recorrer el espacio, descubriendo sus conexiones, promoviendo experiencias y entendiendo a través de ellas el por qué de cada exposición, esto otorgará a los organizadores y personal de los museos un vasto rango de perspectivas con la finalidad de dar una orientación con el contenido, relacionando temas y subtemas de cada exposición.

Se considera también que es deseable desarrollar estrategias para fortalecer el vínculo dialógico entre exposiciones y usuarios finales donde las cédulas: a) Revelen algún aspecto importante además de lo que ya se pueda ver explícitamente, b) Posibiliten, de cierta manera, la provocación al receptor de la exposición con frases para hacerlo pensar de otras formas, c) Otorguen microhistorias para que no se sobresaturen con fechas y hechos, d) Estén realizadas por un especialista enfocado en los usuarios finales compartiendo la pasión por el tema y e) Sean breves, ya que cada visitante tiene intereses particulares y una capacidad un tanto limitada para leer textos largos.

Añadiendo a estas consideraciones, se plantea que cada cédula funcione de manera independiente con un propósito específico pero, que a la par, sostenga una narrativa de manera conjunta para que otorgue un sentido integral de la exposición. Es posible que, de este modo, puedan establecerse conexiones emocionales e intelectuales entre los visitantes y los múltiples contenidos de las exposiciones otorgando una mezcla de estilos que van desde el técnico, histórico, científico, periodístico y creativo; dependiendo del argumento curatorial y aunque dichos estilos puedan mezclarse, se necesitan dirigir los mensajes tanto a los objetivos específicos de cada exposición como a sus públicos para poder ser interpretados eficientemente.

Se considera entonces indispensable que se ubique claramente tanto el lenguaje como el concepto visual para aplicarlo de forma eficaz al diseño de una exposición de manera íntegra, por lo tanto, el diseño gráfico adaptado a un museo necesita un lenguaje particular para diferenciar, por ejemplo, una exposición dentro del propio museo respetando el diseño institucional del mismo en su totalidad, sin perder de vista la experiencia dialógica con el visitante. 


\section{Museología a través del diseño, líneas de tiempo}

Es importante recordar que en la década de 1980 el impacto de nuevas tecnologías llegó a los medios de comunicación y en especial a los medios gráficos. Fue posible utilizar nuevos recursos visuales generando herramientas innovadoras para atraer públicos con renovados hábitos de lectura, donde la supremacía de la imagen comenzó a ser más latente, caracterizando entonces una lectura fragmentada pero veloz a través de infografías, las cuales forman parte de los elementos de la comunicación visual donde se representan, resumen y explican temas específicos. Points (2007) menciona que la esencia del diseño de información es organizar, analizar, solucionar, entender y diseñar. Su objetivo prioritario se basa en la traducción de información compleja tal como datos no organizados, estructurándolos y dando como resultado final información con sentido y de fácil acceso. Dentro de las infografías, uno de los recursos más usados en los museos y sus exposiciones son las Líneas de Tiempo, siendo que éstas ayudan primero a establecer o explicar el contexto histórico ya sea de una obra, objeto, de un artista o de toda la exposición. Segundo, permiten resumir información extensa de manera sencilla a través de un producto visual y, finalmente, otorgan de manera cronológica -si se desea- varias capas de conocimiento al mismo tiempo. Esto implica también que las líneas de tiempo tienen implícito un carácter educativo dado que impactan tanto el acceso a la información como la fácil absorción del conocimiento, indiscutiblemente también generan un vínculo dialógico entre exposición y visitante.

A partir de los grandes desarrollos tecnológicos ahora no sólo se observa en líneas de tiempo información gráfica, estas líneas también incluyen medios audiovisuales para enriquecer la interacción de los usuarios con la información incluida en ellas, así como con el propio espacio museístico. Un ejemplo de esto se encontró en el Museo Alemán de Higiene de Dresde que junto con ART+COM desarrollaron para la exposición "Trabajo. significado y exposición” en 2009 una enorme línea de tiempo llamada Statistics Strip que estaba destinada a:

...visualizar y procesar grandes volúmenes de datos y hechos. Como un tema recurrente, la tira de aluminio negro se pliega a lo largo de las paredes y se ensancha ocasionalmente en gráficos y tablas de varios tipos: líneas, superficies y columnas 3-D, muestran información de fondo extensa, transparente y fácil de entender con detalles sorprendentes. Además [existen] siete estaciones de medios interactivos con proyecciones que están integradas en la franja, donde los visitantes pueden cambiar diferentes parámetros girando perillas para recuperar varios datos. 50 monitores pequeños contrastan las figuras en la pared con perspectivas individuales: usando pantallas táctiles, las entrevistas con más de 100 personas se integran en la "tira de estadísticas". (Helling, 2021, s/p) 


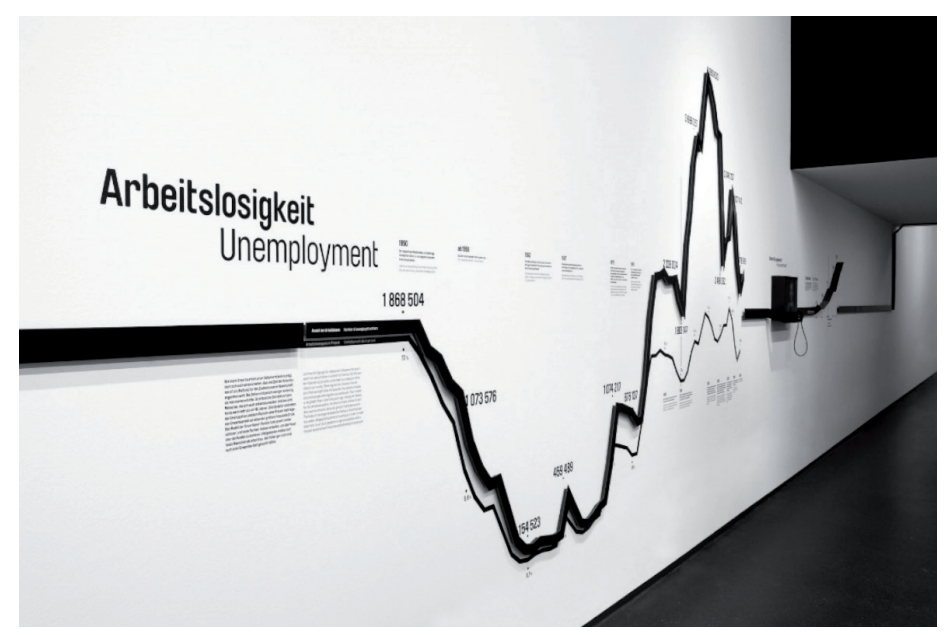

Figura 1. Vista general de Statistics Strip

Recuperado de http://stefanhelling.com/projects/statics-strip

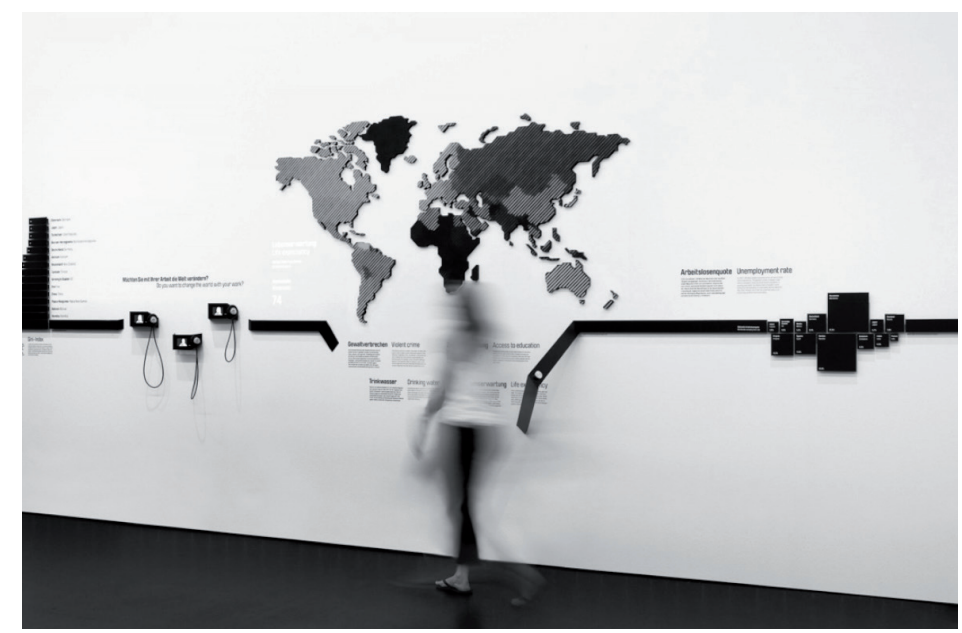

Figura 2. Usuaria interactuando con mapa de Statistics Strip Recuperado de http://stefanhelling.com/projects/statics-strip

Como es posible observar en las Figuras 1 y 2, los visitantes de dicha exposición tenían la posibilidad de interactuar con la línea de tiempo. Claudia Gianetti explica sobre la hipermedia: 
La voluntad de optimizar el proceso de interacción y el tiempo de reacción sujeto-máquina tiene por resultado la potenciación de la visualización y de la percepción, a partir de otros sentidos humanos, de la información existente y manejada por el ordenador [incluyendo otros tipos de soportes como audios, videos, etc.] (2002, p.114)

De acuerdo a estos ejemplos, a mi parecer Statistics Strip cumplía con el concepto de integración en el arte, el cual puede ser entendido como una mezcla de tecnología y estructuras artísticas que da como resultado una forma de expresión totalmente híbrida (Marinetti, 2002). Se puede decir que aquellas teorías que han definido al arte como un medio de comunicación, han establecido la relación entre un emisor de algún mensaje, el vehículo del mensaje y su receptor. Y aunque dicho lineamiento introduzca en esta relación otro término que es el código conforme al cual se produce y capta el mensaje, la tríada fundamental se ha mantenido en los diversos enfoques estéticos.

Por otra parte, Norbert Wiener (fundador de la cibernética) afirmó que sólo podía comprender la sociedad por medio del estudio de mensajes y de las facilidades de la comunicación. Se aclara entonces que la cibernética es una ciencia complementaria a las comunicaciones ya que estudia sus soportes basándose en la analogía entre el comportamiento de la máquina y el propio de los organismos biológicos. Por otra parte, Statistics Strip también podría ser vista como una instalación:

[Siendo] por excelencia, el arte de la metáfora. Un despliegue en el espacio de diversos elementos -tales como objetos, imágenes, sonidos, etc.- cumpliendo un papel asociativo un tanto obvio dado que construye una escena, un decorado, una escenografía dedicada a ser habitada por el espectador. (Bonet, 2002, p. 95)

Diez años después de la propuesta del Museo Alemán de Higiene de Dresde y ART+COM en sus espacios propiamente físicos, el Museo del Prado en colaboración con la pinacoteca y la empresa Telefónica lanzó a finales del 2019 una herramienta absolutamente innovadora en su página web cuyas bases son la inteligencia artificial con la que se permite vincular obras de la colección del museo con hechos históricos, culturales y científicos que sucedieron a la par, llamada la Línea del tiempo online:

En la realidad, todo está enlazado y, en consecuencia, cabe construir relatos que subrayen esta cualidad de lo real [...] Podemos preguntarnos ¿es posible construir una historia o una idea universal del Arte desde este rincón [del] Museo del Prado? ¿Podemos, haciendo emerger de las enciclopedias que representan nuestro conocimiento, conectar las obras que representan cualquier saber, sus autores y los acontecimientos históricos que los enmarcan y quizá explican con las obras y autores del Prado cuando ordenamos todo ello en la Línea del Tiempo y descubrir por medio de ella el parentesco en ocasiones evidente entre obras de saberes distintos, las relaciones de influencia entre autores diversos, la urdimbre común, lo que enlaza y vincula a todo eso que considerábamos hasta ahora de un modo distinto y separado? Con la Línea 
del Tiempo, el Museo del Prado ha querido dar una respuesta afirmativa a esta pregunta. Este proyecto ha tenido como objetivo dotar a la colección y autores del Prado de un contexto amplio, histórico e interdisciplinar que los enmarque, explique y universalice; contexto que a la vez permite al Prado y a su colección funcionar como puerta de acceso al conocimiento en su conjunto [...] El Prado puede ofrecer de este modo a todo el que así lo desee una verdadera máquina de estudiar, aprender y de construir relaciones significativas entre las entidades que forman el poblado mundo de la cultura y la historia. (Museo del Prado, 2021, s/p)

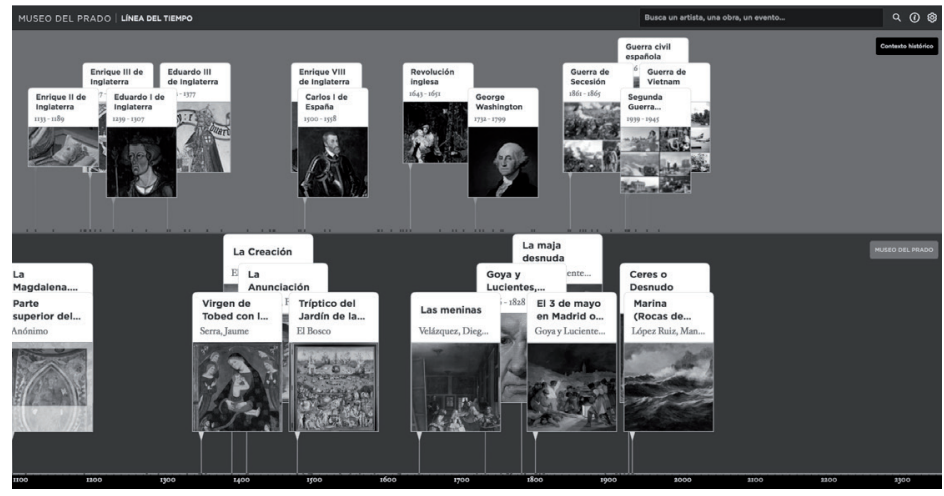

Figura 3. Página inicial de la Línea de Tiempo del Museo del Prado Recuperado de: https://www.museodelprado.es/coleccion/linea-del-tiempo

Explorando la Línea del Tiempo del Museo del Prado por medio del link https://www. museodelprado.es/coleccion/linea-del-tiempo se perciben tres divisiones básicas en la pantalla, la inferior es la línea de tiempo, luego las obras del museo y arriba el Contexto Histórico (Figura 3), entrando a la herramienta de configuración en la esquina superior derecha donde se activan hasta cinco líneas de tiempo simultáneas, se pueden incluir literatura, ciencia, filosofía, arquitectura entre otras opciones para aumentar la información relacionada con cada obra de la colección, ofreciendo de tal forma una exploración aumentada de textos explicativos de una obra (Figura 4). Esto fue posible gracias al motor llamado Comprensión del Lenguaje Natural (NLU en inglés) el cual posibilita el reconocimiento de entidades que distingue y disminuye ambigüedades de los textos para que entonces, dicha inteligencia artificial, consiga separar los principales conceptos en el texto explicativo de las obras. Con ello, los visitantes virtuales podrán escoger desde una obra, un artista y hasta el momento histórico que gusten abriéndose una línea con diferentes pantallas que ampliarán la información con diversas temáticas por medio de los textos del mismo museo así como de Wikipedia. 


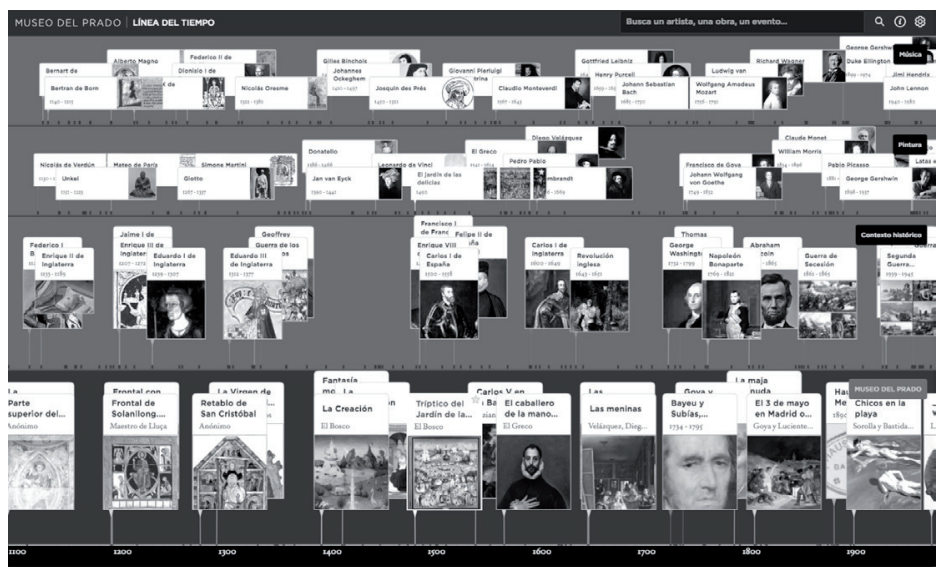

Figura 4. Resultados después de cambiar las opciones de configuración de la Línea de Tiempo del Museo del Prado. Recuperado de: https://www.museodelprado.es/coleccion/linea-del-tiempo

En lo personal se considera que este esfuerzo es un enorme cruce de interrelaciones dialógicas entre textos, soportes tanto analógicos como digitales, tecnología, museología y diseño digital, así como otros aspectos, que dan cabida a muchos de los objetivos museísticos del Museo del Prado, uno de ellos, ofrecer un portal educativo que rompe con el espacio físico permitiendo así una coyuntura de inclusión llegando potencialmente a una población virtual mundial de habla hispana e inglesa que también irá en aumento

\section{El museo virtual}

Resulta importante subrayar que la evolución tecnológica en los últimos veinte años ha tenido un gran impacto en todos los aspectos de la cotidianidad tanto individual como colectiva. Esto ha implicado una modificación en la manera de percibir todo, desde el mundo del arte hasta la forma de comprender espacios de exhibición de diferente índole. Por supuesto, el ámbito museístico ha tenido que acoplarse a las infinitas demandas aprovechando y desarrollando recursos para trasladar sus contenidos físicos a la era digital. Los museos de Estados Unidos fueron pioneros en replicar dichos cambios ya que durante los años ochenta del siglo pasado, orientaron cambios abriéndose a una audiencia cada vez más diversa y mayor. Esto fue exportado a los museos del mundo constituyendo esa gran corriente de apertura y transformación de conceptos. Por lo tanto, los museos modificaron la interpretación que se hacía de sus colecciones más no las cambiaron, reinventaron la difusión para llegar a más usuarios, cambió el diálogo con el público y los visitantes a la vez se empezaron a acostumbrar a esas nuevas formas de contacto. Los términos "virtual" y "museo virtual" empezaron a hacer reverberaciones a partir de la primera conferencia 
titulada Museums an the Web: An International Conference llevada a cabo en 1997 en la ciudad de Los Ángeles. Giannini y Bowen explican:

El concepto «virtual» fue una gran clave para el desarrollo digital del momento. [...] para esa década se hablaba del concepto que la World Wide Web apareció para "reflejar» de otra manera la realidad pero en un mundo digital. Sin embargo, ambas realidades surgieron como mundos diferentes y en competencia entre sí más no como una realidad mixta tal, como la podemos comprender ahora. No obstante, hay que tomar en cuenta que antes de la masificación de los teléfonos inteligentes la mezcla de ambas dimensiones, tanto las reales como las digitales en la vida era mucho más difícil de conjugar. $(2014$, p. 37)

Pongamos la atención entonces a los sitios primerizos de los museos virtuales con sus sitios web y sin duda uno de los factores influyentes para el diseño y su visualización eran los navegadores y su programación específica con lenguajes crípticamente informáticos los cuales influían precisamente en su diseño: en la forma, tamaño, peso de las imágenes, colores, entre otros factores. En síntesis, se resalta que todo esto ha evolucionado de forma exponencial, por lo tanto, los museos se han ido adaptando también a las tecnologías emergentes, han invertido sus recursos con el fin de mejorar sus páginas web y otorgar mejores conexiones con los usuarios.

Con el auge de los museos virtuales, es notorio que la relación que el público ha tenido con las instituciones museísticas se ha modificado pues, por medio del material interactivo la relación unidireccional que se tenía con los museos se convirtió en bidireccional siendo ahora del visitante al museo y ya no necesariamente al revés. Dichos cambios han forzado a los espacios de exhibición a tener un cambio incesante y de alguna manera la relación con los usuarios a través de la web les ha ayudado a reinventarse.

Esto, por supuesto, ha tenido que ir de la mano con la creación y el diseño de las páginas web de los museos, es probable que muchas de ellas hayan iniciado con archivos HTML empleando también hipervínculos. En un inicio, el escribir textos para cualquier página web emergió por la necesidad de utilizar lo que existía en esos momentos en el plano de lo físico pero a la vez, marcó una pauta de organización y de escritura específica.

Con la evolución de las tecnologías y la revolución de la velocidad de conexión, las páginas cuasi inmóviles fueron reemplazándose por unas dinámicas y con una mejor estética, pues empezaron a incorporar menús, imágenes animadas y por supuesto, otorgando diseños mucho más estilizados. A la par ha sido necesario incluir una estructura específica y fácil de usar para los visitantes virtuales donde se indique claramente la organización del contenido, el uso de sus herramientas, es recomendable también insertar tutoriales o guías de uso rápidas para poder navegar tanto en una computadora como en los diferentes dispositivos móviles. Esto marca una pauta dialógica también puesto que existen estudios online donde se demuestra que los sitios web que incluyen mayores plataformas interactivas pueden aumentar la sensación de control de los usuarios (Hoffman \& Novak, 1996). Es un hecho que la aparición de las redes sociales también ha marcado una modificación en cuanto a las relaciones dialógicas entre museos y usuarios con las cuales se tienen que generar experiencias inclusivas. Duarte afirma al respecto: 
... el panorama comunicativo de las instituciones culturales demuestra que los museos están vivos y deseosos de repercutir en el día a día de la población global. Las redes sociales permiten el florecimiento de un público heterogéneo, así como su adaptación cronológica de la web 2.0. [Se han empleado] las redes como Facebook, Twitter e Instagram para interactuar por medio de compartir imágenes, videos, opiniones, noticias de interés o de ocio, etc. Dichas interacciones suceden principalmente mediante tres modelos de comunicación: el uno a uno (de usuario a usuario), el uno a muchos (institución a usuario) y de muchos a muchos (conocimiento a conocimiento-wikis) ... Uno de los principales beneficios de las redes sociales es que dan acceso a un mayor número de usuarios a la colección de la institución cultural, con lo que se permite crear un híbrido entre la experiencia clásica del museo como espacio físico y el acceso inmediato a materiales complementarios. (2016, pp. 216-220)

A partir de este planteamiento, dicho autor también recomienda integrar las redes sociales dentro del plan general de comunicación y promoción de la institución museística con lo cual se puede establecer una sinergia entre estas plataformas digitales y los usuarios, delimitando en primer lugar los objetivos que se desean lograr con las diferentes redes sociales difundiendo tanto el contenido del museo como también iniciando conversaciones con potenciales usuarios para poder aumentar su interés.

Esto permite la interacción instantánea entre instituciones y personas propiciando un diálogo constante, no cabe duda que con la aparición de la world wide web se han roto fronteras de espacio y tiempo lo cual ha permitido establecer también comunicación en tiempo real con personas en cualquier lugar del mundo, lo cual significa que la difusión de mensajes es ilimitada. Las tecnologías de la información y en especial los dispositivos móviles inteligentes, ofrecen a los museos grandes oportunidades para poder responder a los requerimientos de las sociedades hiperconectadas. Entonces, el acceso a los museos toma una dimensión muy diferente y amplia, ofreciendo las posibilidades de interactividad y el desvanecimiento de barreras físicas, por lo cual, los museos a través de una computadora, tableta o celular, están abiertos a todo aquel interesado que tenga una buena conexión a internet permitiendo que las exposiciones sean accesibles en cualquier momento.

\section{Experiencias con dos exposiciones virtuales}

Para este apartado es imperante analizar un poco la curaduría de contenidos museísticos en formatos digitales, dado que los museos han puesto a disposición del público sus colecciones con diversos fines de investigación, académicos, así como para expandir una interacción mayor con los usuarios y, al mismo tiempo, las instituciones museísticas siguen desarrollando comunidades propias tanto de forma local como internacional a través de sus plataformas digitales, lo cual permite alcances que hace sólo treinta años eran imposibles de imaginar. 
Actualmente, va desapareciendo día con día el desfase entre lo que contiene un museo y lo que se muestra al público mediante sus páginas web además, la contingencia global dada en el año 2020 por el COVID-19 aceleró exponencialmente tanto la implantación como el mejoramiento de las plataformas para digitalizar sus contenidos. Es probable también que dentro del marco digital, los museos puntualicen aún más los múltiples segmentos de usuarios a los cuales sus exposiciones están dirigidas.

Por otra parte, no cabe la menor duda que el diseño gráfico a través del diseño web de las exposiciones ha tenido sus propios retos y progresos, dado que ha sido una constante la evolución y las nuevas plataformas han sido más nobles para poder crear interacciones con los usuarios. No obstante, se debe volver al punto de partida analizado anteriormente que es el texto curatorial. Todo inicia con el mencionado texto a partir del cual se diseña una estructura y orden para su ejecución. Podría considerarse, tal vez, que el medio en sí mismo, es decir, las páginas web se convierten en las plataformas de diálogo museousuarios por medio de la interacción.

Entrando en práctica, para este texto se decidió explorar la experiencia de usuario con dos exposiciones virtuales para comprobar la conexión dialógica museo-diseño digital-usuario, añadiendo también que dicha experiencia fue también vivida por estudiantes dentro de una de las clases de un taller virtual que ofrecí a finales de Febrero del 2021.

La primera visita fue al Museo de Arte Moderno (MAM) que forma parte de la red de museos del Instituto Nacional de Bellas Artes (INBA) ubicado físicamente en la Ciudad de México, a través del link https://inba.gob.mx/sitios/recorridos-virtuales/museo-de-artemoderno/.

En general se puede describir que el recorrido virtual tiene características $3 \mathrm{D}$ y aunque al abrir dicho enlace lo primero que aparece son las instrucciones instantáneas para utilizar el mouse de la computadora en la interfaz (Figura 5), realmente fue difícil manejarla pues pareciera ser como si las flechas estuvieran al revés. Conforme se avanzó, se pudo aprender y tener un mayor control. En realidad son pocos los lugares y las salas que muestra el portal digital (Figura 6), dentro de las mismas, es posible ver varias piezas de la colección, pero no todas, así como tampoco se podían ver las cédulas. Por otra parte, también se puede hacer un recorrido por las diferentes esculturas que están en los jardines del museo. Cabe resaltar que este link no está vinculado con el portal oficial de la página de MAM lo cual se considera una lástima pues si se hiciera, es muy probable que tenga mucho más afluencia de usuarios. Para concluir, se destaca el gran esfuerzo del INBA para crear estos recorridos virtuales pero que, por supuesto, pueden mejorarse aún más ya que la experiencia como usuaria se quedó un tanto limitada. Cabe aclarar que al grupo de estudiantes con los que se compartió el recorrido dentro de la clase les gustó mucho a pesar de las limitaciones señaladas del propio recorrido. 


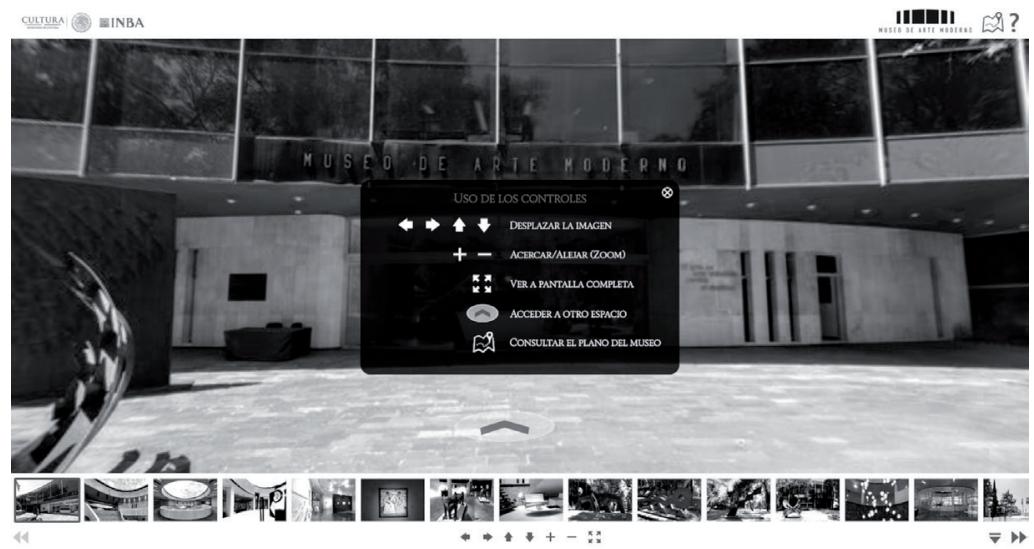

Figura 5. Instrucciones del uso del recorrido virtual del Museo de Arte Moderno Recuperado de https:/inba.gob.mx/sitios/recorridos-virtuales/museo-de-arte-modermo

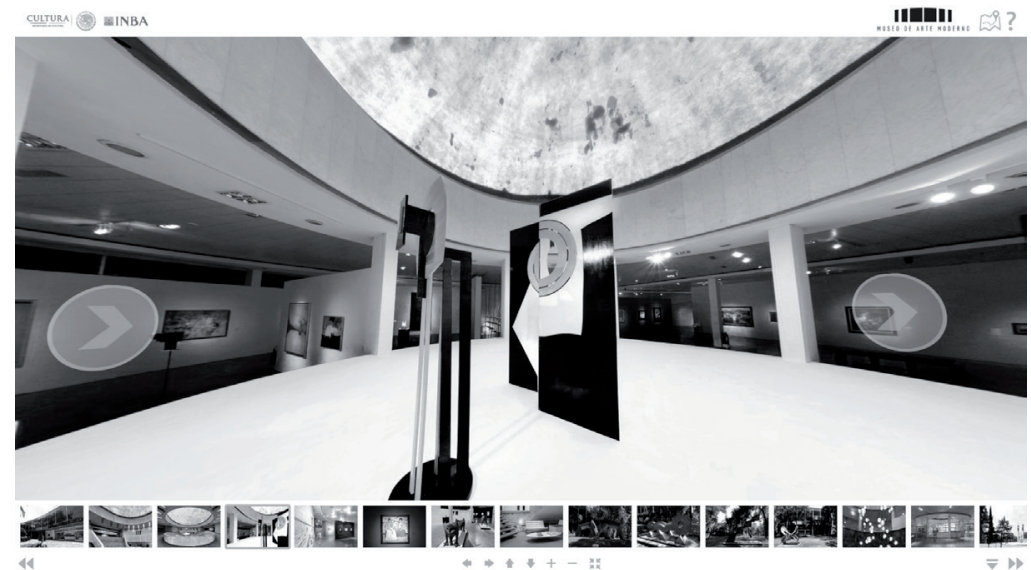

Figura 6. Centro de sala del recorrido virtual del Museo de Arte Moderno

Recuperado de https://inba.gob.mx/sitios/recorridos-virtuales/museo-de-arte-modermo

La siguiente visita fue al Museo de Arte Contemporáneo de Barcelona (MACBA) con el link https://www.macba.cat/es/arte-artistas/muestra-permanente/visita-virtual se pudo ingresar a la visita virtual de la muestra permanente Un siglo breve: Colección MACBA. Es indispensable observar que esta institución está utilizando una plataforma digital de Matterport (Figura 7). 
Matterport es una empresa de tecnología audiovisual de inmersión que ofrece sistemas integrales para la creación, modificación, distribución y navegación de versiones $3 \mathrm{D}$ y realidad virtual (RV) de lugares del mundo físico [trasladados a] Internet con dispositivos móviles y [a través también] de gafas de realidad virtual... Acaba de anunciar el lanzamiento de una nueva cámara todo en uno para hacer este trabajo, la Pro2 3D, modelo que junto con Matterport Cloud, ofrece a sus usuarios una solución integral para la captura, distribución y visualización de propiedades en 2D, 3D y RV... [con los que] precisan obtener fotografías de alta resolución con calidad de impresión e imágenes en 3D... este nuevo modelo, de 134.2 megapíxeles, permite generar fotografías para impresión $(4 \mathrm{~K})$ y un plano interactivo en $3 \mathrm{D}$ a todo color... Otra ventaja de la cámara Pro2 es que captura toda una propiedad en un modelo 3D que se puede revisar en línea en todo momento, lo que permite a los usuarios generar fotos adicionales sin tener que hacer capturas nuevas. (DigitalCamera.es, 2021, s/p)

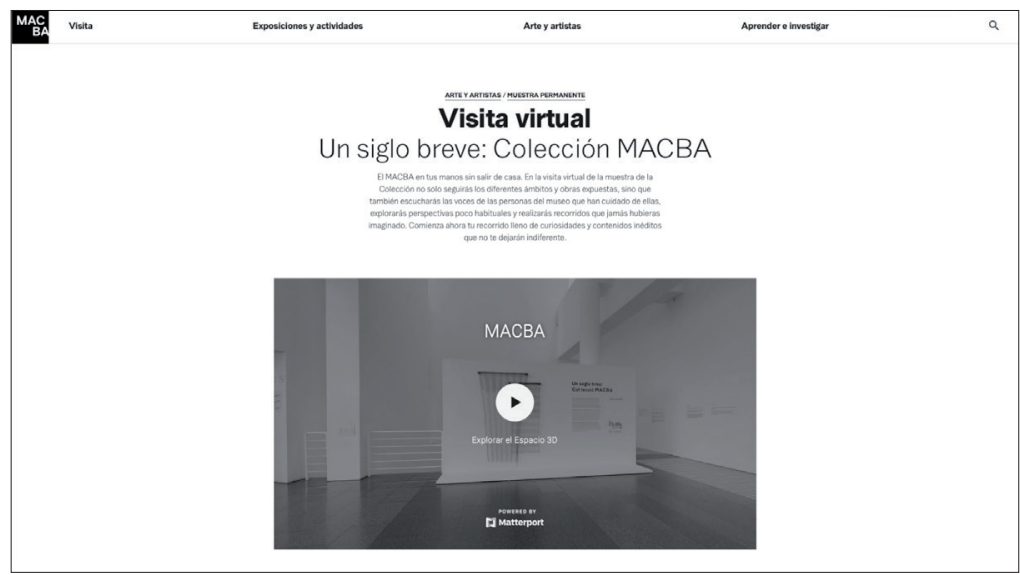

Figura 7. Página de inicio de la visita virtual de la colección MACBA

Recuperado de: https://www.macba.cat/es/arte-artistas/muestra-permanente/visita-virtual

Toda la descripción y facilidades detalladas que fueron asignadas a la plataforma pudieron experienciarse. El recorrido virtual a través de dicha plataforma fue extraordinario, las fotos son de una excelente calidad HD sin duda alguna, la interfaz para mover el mouse de la computadora fue muy fácil de controlar después de algunos minutos de uso. La interfaz contiene desde un principio un mapa general del museo para iniciar el recorrido, en ciertas piezas incluía también descripción de la cédula de la obra (Figura 8), así como medios alternativos que nos llevaron tanto a escuchar música como a ver videos explicativos de la exposición. Todo lo antedicho enriqueció nuestra visita y experiencia del recorrido virtual 
ampliándose de alguna manera nuestra curiosidad y diálogo con la exposición misma. En verdad nadie quería salir de la exposición virtual, todos queríamos seguir explorándola pero tuvimos que finalizar el recorrido por horarios y temas a cumplir del mismo taller. Se observó en los estudiantes que estaban extremadamente emocionados, fue de alguna manera nuestro primer acercamiento a estas plataformas.

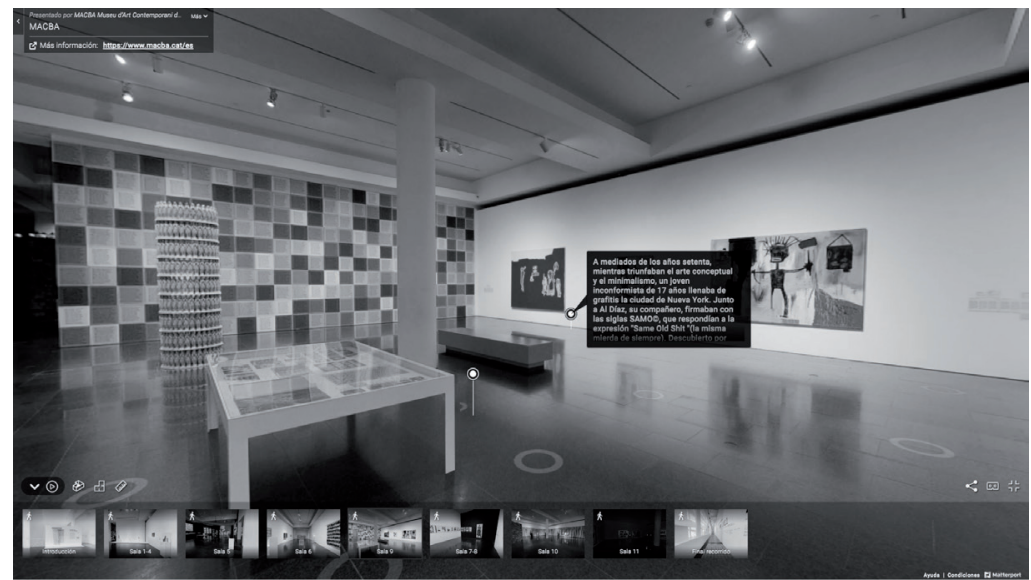

Figura 8. Cédula explicativa de una obra dentro de la visita virtual del MACBA

Recuperado de https://www.macba.cat/es/arte-artistas/muestra-permanente/visita-virtual

A través de ambas experiencias, se subraya que la digitalización del museo desempeña un importante papel en la conservación y preservación de las colecciones en sus diferentes exposiciones, que seguramente tendrán desafíos específicos tanto museológicamente hablando como con el propio diseño digital; pero al mismo tiempo dichos retos otorgan otras posibilidades de conversación y relaciones dialógicas multimediales que fortalecen de alguna manera el vínculo museo-usuario.

\section{Conclusión}

Uno de los grandes objetivos de un museo es su público siendo su finalidad primaria el de comunicar a través de una exposición determinada, el diseño gráfico adaptado a la planeación y creación de una exposición es fundamental para establecer dicha comunicación construyendo puentes dialógicos accesibles y claros entre la exposición y sus visitantes, generando confianza para poder apostar a múltiples propuestas visuales, es claro entonces que el diseñar una exposición genera colaboraciones con diversas disciplinas. 
Por su parte, el diseño de una museografía web es un campo en expansión de una relevante investigación y desarrollo, la cual personalmente se considera también una gran plataforma de diálogo entre las exposiciones y el contacto directo con los usuarios en cualquier parte del mundo donde puedan ingresar a internet. A continuación, se enuncian las ventajas más importantes de las exposiciones y recorridos virtuales: contacto directo con los visitantes, acercamiento inmediato a la población juvenil y gran facilidad de acceso lo cual puede generar un mayor gusto a los museos tanto en su parte física como digital incidiendo en más visitas.

\section{Lista de Referencias}

Bonet, E. (2002). La instalación como hipermedio. En Gianetti, C. Media Culture. Barcelona: L'Angelot: 95

DigitalCamera.es (2017). Matterport Pro2 3D: las mejores visitas virtuales. Recuperado el 20 de Marzo 2021 de http://www.digitalcamera.es/novedades/matterport-pro2-3d/

Duarte. M. (2016). Públicos y Redes sociales. En Pérez Castellanos, L. (coord.) Estudios sobre públicos y museos, Vol I, Publicaciones Digitales ENCRYM-INAH, México: 216-220

Gianetti, C. (2002). Estética digital. Sintopía del arte, la ciencia y la tecnología. Barcelona: L'Angelot: 114

Giannini, T. \& Bowen J. (2014). Museums and Digital Culture New Perspectives and Research. New York: Springer.

Helling, Stefan. (s.f.) Statistcs Strip. Recuperado el 13 de Marzo 2021 de http://stefanhelling. com/projects/statistics-strip

Hoffman D. \& Novak T. (1996). Marketing in Hypermedia Computer-Mediated Environments: Conceptual Foundations. Journal of Marketing (3): 50-68.

International Council of Museums (ICOM) (s.f.). Recuperado el 19 de Febrero 2021 de https://icom.museum/en/resources/standards-guidelines/museum-definition/

Marinetti, F. (2002). El Cine Futurista. En Packer. R. \& Jordan, K. Multimedia. From Wagner to virtual reality. New York: Norton

Mateos, S. (2011). ¿Sólo informar o también persuadir? Museos y publicidad en España: Pensar la Publicidad, 1 (5): 203-205

Museo del Prado. (s.f.). La línea de tiempo del Prado: una visita contextual, histórica e interdisciplinar de la colección del Prado. Recuperado el 22 de Marzo 2021 de https://www. museodelprado.es/grafo-de-conocimiento/linea-de-tiempo

Ochoa, H. (2009). El carácter dialógico de la hermenéutica de Schleiermacher. Su fundamento y sentido. Instituto de Filosofía Pontificia Universidad Católica de Valparaíso. Recuperado el 4 de Febrero 2021 de http://www.scielo.org.co/pdf/ef/n39/n39a05.pdf

Oklahoma Museums Association (OMA) (s.f.). Recuperado el 19 de Febrero 2021 de https:// www.okmuseums.org/resources/starting-a-museum/

Pontis, S. (2007). La historia de la esquemática en la visualización de datos. Recuperado el 4 de Marzo 2021 de https://www.academia.edu/9550451/La_historia_de_la_ esquem\%C3\%A1tica_en_la_visualizaci\%C3\%B3n_de_datos 
Ramírez, S. (2016). Cédulas y Textos. En Pérez Castellanos, L. (coord.) Estudios sobre públicos y museos, Vol I, Publicaciones Digitales ENCRYM-INAH, México: 132-133

Real Academia Española (RAE). (2020). Diccionario de la lengua española. Recuperado el 17 de Febrero 2021 de https://dle.rae.es/museo?m=form

\begin{abstract}
Today museum's exhibitions provide stories with a beginning, a development to reach an end, this facilitates the understanding of a narrative that was previously delimited to have a solid curatorial argument. Both the reading and the thematic content of the museums are possible aspects to be perceived in the exhibition's discourses presented with routes that include multiple objects together with analog and digital audiovisual supports. Through a great museological work, these enclosures enable spaces for their visitors to experience in different ways the story they wish to give and one of their great allies has been design by synthesizing stories and information in an effective way with time lines for example. Such dialogic relationship has had to be expanded to create virtual museums and exhibitions so by clicking on a computer or cell phone it is possible to take a tour of national and international exhibitions. This has given immense challenges for the physical museum's stories could set down on web pages with attractive designs and digital supports that have evolved along with technology itself.
\end{abstract}

Keywords: Dialogic - Museology - Design - Virtuality - Integration - Interaction

Resumo: As exposições dos museus hoje proporcionam histórias com um principio e um desenvolvimento para chegar a um final, o que facilita a compreensão de uma narrativa que foi delimitada previamente para ter uma sólida argumentação curatorial. Tanto a leitura como o conteúdo temático dos museus são aspectos possíveis de serem percebidos nos discursos expositivos apresentados nas salas de exibição com percursos que incluem múltiplos objetos a par de suportes audiovisuais analógicos e digitais. Por meio de um grande trabalho museológico, esses recintos permitem que seus visitantes experimentem de diferentes formas os temas e os tópicos que desejam transmitir e um de seus grandes aliados foi o design, sintetizando relatos e histórias de maneira eficaz, como linhas do tempo. Tal relação dialógica teve que ser ampliada para criar museus e exposições virtuais de forma que a partir de um "clique" no computador ou no celular seja possível fazer um tour por exposições nacionais e internacionais. Isso criou desafíos imensos para que os relatos museológicos físicos fossem colocados em páginas da web com designs atraentes e suportes digitais que evoluíram junto com a própria tecnologia.

Palavras chave: Dialógica - Museologia - Design - Virtualidade - Integração - Interação

[Las traducciones de los abstracts fueron supervisadas por el autor de cada artículo] 